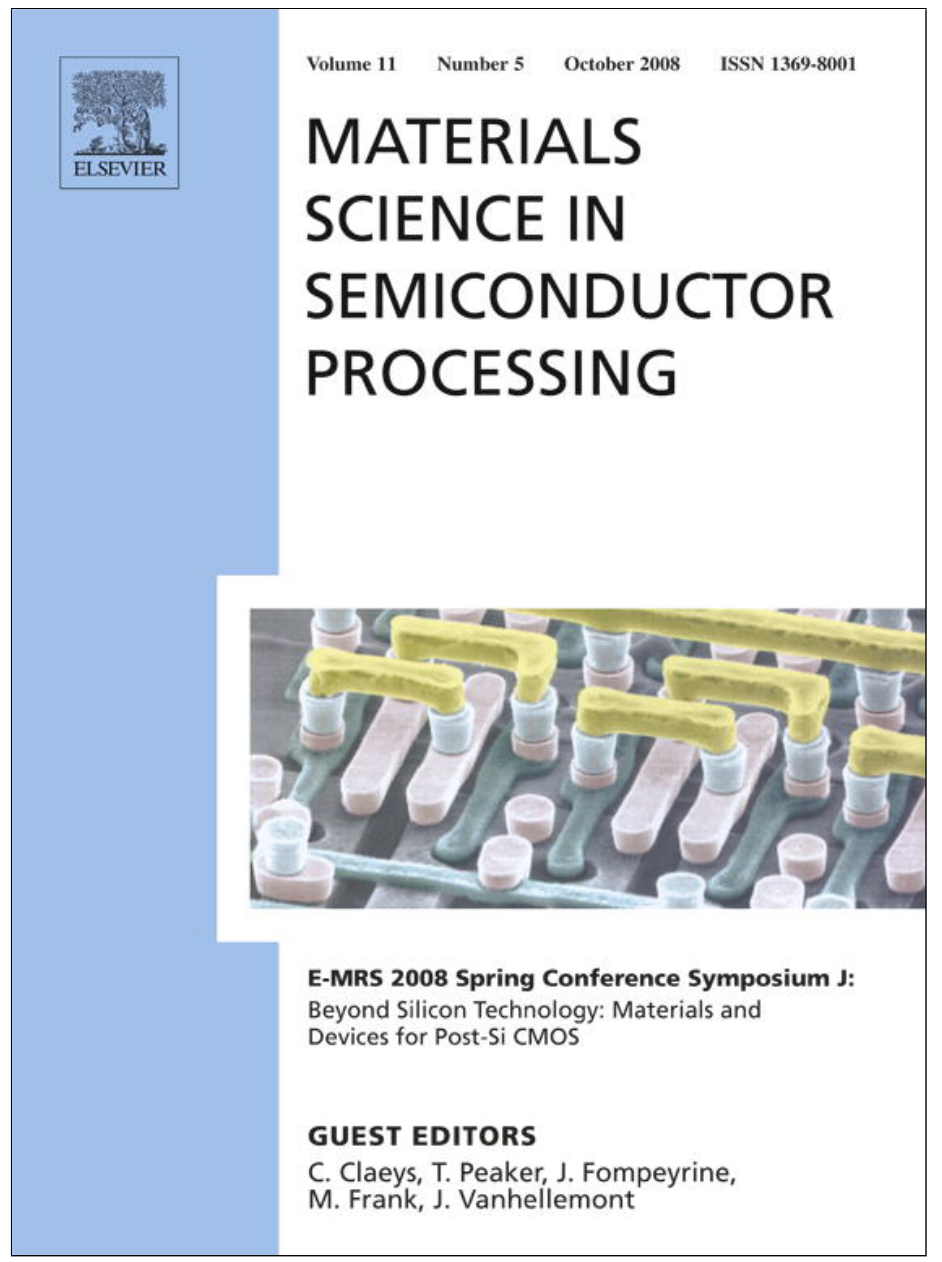

This article appeared in a journal published by Elsevier. The attached copy is furnished to the author for internal non-commercial research and education use, including for instruction at the authors institution and sharing with colleagues.

Other uses, including reproduction and distribution, or selling or licensing copies, or posting to personal, institutional or third party websites are prohibited.

In most cases authors are permitted to post their version of the article (e.g. in Word or Tex form) to their personal website or institutional repository. Authors requiring further information regarding Elsevier's archiving and manuscript policies are encouraged to visit:

http://www.elsevier.com/copyright 


\title{
High-quality NiGe/Ge diodes for Schottky barrier MOSFETs
}

\author{
M.K. Husain *, X.V. Li, C.H. de Groot \\ Nanoscale Systems Integration, School of Electronics and Computer Science, University of Southampton, Southampton SO171BJ, United Kingdom
}

\section{A R T I C L E I N F O}

Available online 23 January 2009

Keywords:

Schottky barrier MOSFET

Electrodeposition

Leakage current

\begin{abstract}
A B S T R A C T
Schottky barrier (SB) Ge channel MOSFETs suffer from high drain-body leakage at the required elevated substrate doping concentrations to suppress source-drain leakage. Here, we show that electrodeposited $\mathrm{Ni}-\mathrm{Ge}$ and NiGe/Ge Schottky diodes on highly doped Ge show low off current, which might make them suitable for SB-MOSFETs. The Schottky diodes showed rectification of up to five orders in magnitude. At low forward biases, the overlap of the forward current density curves for the as-deposited $\mathrm{Ni} / n$-Ge and NiGe/n-Ge Schottky diodes indicates Fermi-level pinning in the Ge bandgap. The SB height for electrons remains virtually constant at $\sim 0.52 \mathrm{eV}$ (indicating a hole barrier height of $\sim 0.14 \mathrm{eV}$ ) under various annealing temperatures. The series resistance decreases with increasing annealing temperature in agreement with four-point probe measurements indicating the lower specific resistance of NiGe as compared with $\mathrm{Ni}$, which is crucial for high drive current in SB-MOSFETs. We show by numerical simulation that by incorporating such high-quality Schottky diodes in the source/drain of a Ge channel PMOS, highly doped substrate could be used to minimize the subthreshold source to drain leakage current.
\end{abstract}

(c) 2008 Elsevier Ltd. All rights reserved.

\section{Introduction}

Ge channel MOSFETs are considered as promising devices for future high-speed CMOS technology as they offer high carrier mobilities suitable for large drive current. Schottky barrier (SB) source/drain MOSFETs overcome the problems faced by the conventional transistor scaling caused by the stringent conditions required for doping with low series resistance. The Ge-based SB-MOSFETs, however, suffer from increased leakage currents due to its narrow bandgap and low Schottky barrier height [1-3]. We have recently shown that $\mathrm{Ni}-\mathrm{Si}$ diodes prepared by electrodeposition exhibit superior properties to physical vapour deposition [4,5]. In this work, we show that electrodeposited $\mathrm{Ni}-\mathrm{Ge}$ and NiGe-Ge Schottky diodes on highly doped Ge exhibit near ideal Schottky barrier behaviour with low off current. The

\footnotetext{
* Corresponding author. Tel.: +4423 80597389 .

E-mail address: mkh05r@ecs.soton.ac.uk (M.K. Husain).
}

experimental data of the diodes are used to calibrate numerical simulations of the Ge SB-MOSFET. At short channel lengths, SB-MOSFETs also suffer from source to drain leakage currents. We show that highly doped Ge substrate is the key to limiting subthreshold source to drain leakage currents. The low off current of the SBs on highly doped substrate might make them suitable for minimizing junction leakage current at the drain/body of SB-MOSFETs.

\section{Experimental techniques}

For the fabrication of $\mathrm{Ni}-\mathrm{Ge} \mathrm{SBs}$, antimony-doped $(0.005-0.02 \Omega \mathrm{cm}, 0.13-0.15$ and $2-2.4 \Omega \mathrm{cm})(100) \mathrm{Ge}$ wafers were taken as the starting materials. Square patterns of sizes from 10 to $400 \mu \mathrm{m}$ were transferred to the photo-resist-coated substrates by conventional lithography. The back ohmic contacts were defined by $\mathrm{Au}-\mathrm{Sb}$ evaporation and annealing the samples in a $\mathrm{H}_{2} / \mathrm{N}_{2}$ inert atmosphere. Subsequently, a 20:1 buffered HF dip for $30 \mathrm{~s}$ followed by DI water dip was performed to remove 
any native oxides. For electrodeposition, a $\mathrm{Ni}$ sulphate bath and an Autolab AUT72032 potentiostat three-electrode system with a Pt counter electrode and a saturated calomel reference electrode (SCE) were used. The deposition potential ranged from 1.10 to $1.15 \mathrm{~V}$ (against the SCE) for the various Ge substrates. The film thickness was monitored during electrodeposition by observing the charge accumulated at the cathode. Current $(I)$-voltage $(V)$ and capacitance $(C)$-voltage $(V)$ characteristics measurements were performed using a Hewlett Packard 4155A semiconductor parameter analyzer and a Hewlett Packard 4280A, $1 \mathrm{MHz}$, C Meter/C-V plotter. Germanidation of the $\mathrm{Ni}$ films was performed for $20 \mathrm{~min}$ in the anneal chamber at temperatures ranging from 300 to $500^{\circ} \mathrm{C}$. The various film thicknesses were measured using scanning electron microscopy (SEM) on a cross-section of the electrodeposited film.

\section{Experimental results}

Typical current density $(J)$ versus applied voltage $(V)$ characteristics of electrodeposited $\mathrm{Ni}-\mathrm{Ge} \mathrm{SBs}$ for three different substrate resistivities $(\rho 1=2-2.4, \rho 2=$ $0.13-0.15$ and $\rho 3=0.005-0.02 \Omega \mathrm{cm}$ ) and of $10 \mu \mathrm{m}^{2}$ contact area are presented in Fig. 1. A high-quality rectifying behaviour is observed for the SBs. For the highly resistive $(\rho 1) \mathrm{Ge}$, excellent SBs are achieved with very low reverse bias current, $\sim 5$ orders of magnitude smaller than the forward bias current at $1 \mathrm{~V}$ bias. Tunneling effects of this SB is negligible in the reverse bias. SBs on the medium resistive $(\rho 2)$ Ge showed similar rectifying behaviour with a little tunneling current in the reverse direction. On the lowly resistive substrate $(\rho 3), \mathrm{Ni} / \mathrm{Ge}$ SB showed increased tunneling effects in the reverse bias. However, even these diodes showed excellent rectifying behaviour with all currents explained by standard thermionic emission (TE) and thermionic field emission theories. The reverse bias current is $\sim 5$ orders in magnitude smaller than the forward bias current. This is a significant achievement over similar works done in literature [6,7] where Schottky diodes grown by evaporation technique exhibited

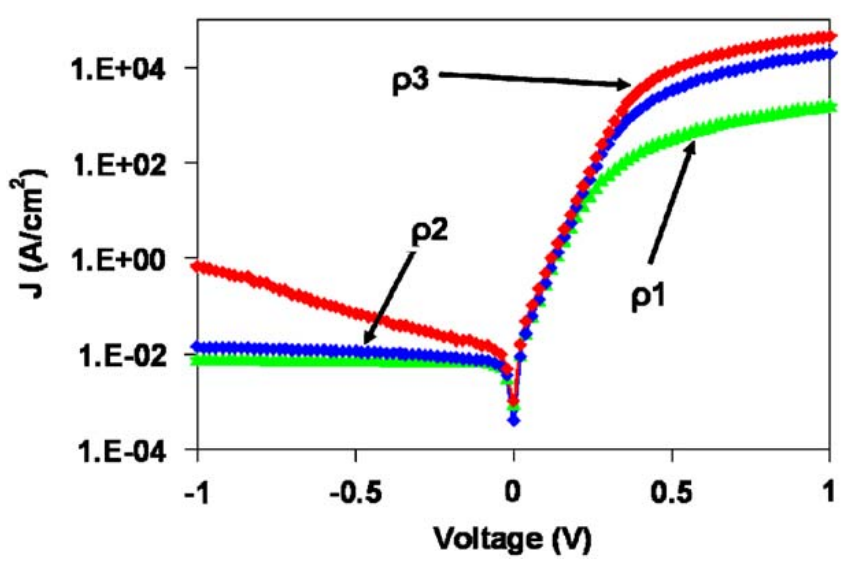

Fig. 1. $J-V$ characteristics of the $\mathrm{Ni} / \mathrm{Ge}$ Schottky diodes $\left(10 \mu \mathrm{m}^{2}\right.$ contact) as a function of $\mathrm{Ge}$ resistivities $(\rho 1=2-2.4, \quad \rho 2=0.13-0.15$ and $\rho 3=0.005-0.02 \Omega \mathrm{cm}$ ). rectification of only 2-3 orders even on highly resistive Ge substrates.

From the $J-V$ curves in Fig. 1, the Ni/Ge Schottky electron barrier height $\left(\Phi_{n}\right)$, ideality factor $(\eta)$ and series resistance $\left(R_{\mathrm{S}}\right)$ can be extracted assuming the TE model in the forward bias. The calculated Schottky barrier parameters are presented in Table 1 for all type of substrates. For these calculations, Richardson constant $\left(A^{*}\right)$ of $50 \mathrm{~A}$ $\mathrm{cm}^{-2} \mathrm{~K}^{-2}$ was used. It is seen from Table 1 that the Schottky barrier heights are virtually constant for the Ge substrates of various resistivities. The low ideality factors indicate thermionic emission to be the dominant current conduction mechanism in the forward bias for the SBs on different substrates.

$C-V$ measurements of SBs on Ge were performed for $A^{*}$-independent measurement of the SB height. An inverse square capacitance versus voltage characteristic is shown in Fig. 2 for an SB on the lowly resistive $(0.005-0.02 \Omega \mathrm{cm})$ Ge substrate and having a contact area of $400 \mu \mathrm{m}^{2}$. As expected, a straight line is observed, and from its intercept on the voltage axis the SB height $\left(\Phi_{n}\right)$ is calculated to be $0.53 \mathrm{eV}$ [8]. Furthermore, from the slope of this characteristic, the Ge doping concentration can be extrapolated. A value of $2.9 \times 10^{17} \mathrm{~cm}^{-3}$ is obtained corresponding to a resistivity of $0.009 \Omega \mathrm{cm}$, which matches the specification of the Ge substrate. Similar $C-V$ measurements were performed on SBs on the medium $(0.13-0.15 \Omega \mathrm{cm})$ and highly $(2-2.4 \Omega \mathrm{cm})$ resistive $\mathrm{Ge}$ and barrier heights $\left(\Phi_{n}\right)$ of 0.53 and $0.56 \mathrm{eV}$ and substrate doping densities of $1.45 \times 10^{16}$ and $8.7 \times 10^{14} \mathrm{~cm}^{-3}$ were obtained, respectively.

The electrodeposited Ni films over Ge were annealed for $20 \mathrm{~min}$ at temperatures ranging from 300 to $500{ }^{\circ} \mathrm{C}$

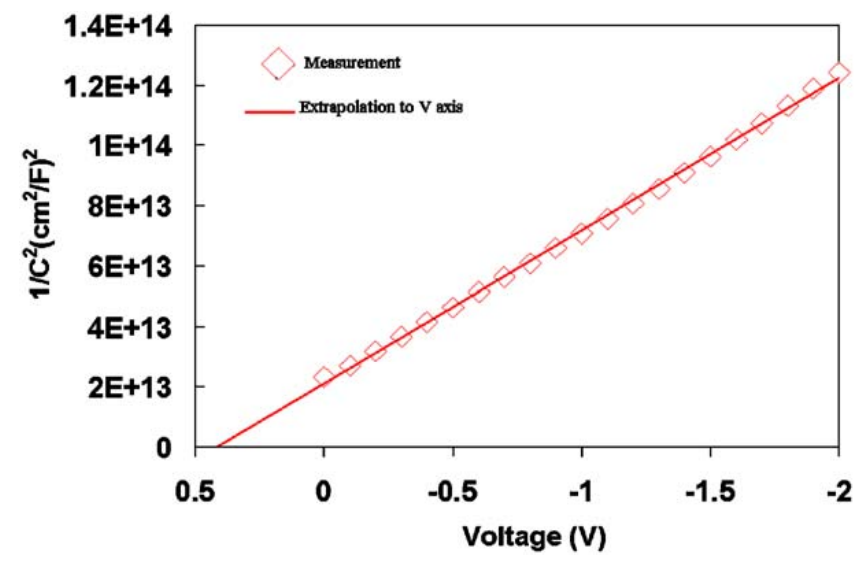

Fig. 2. $C^{-2}-V$ curve of an electrodeposited $\mathrm{Ni}-\mathrm{Ge}(0.005-0.02 \Omega \mathrm{cm})$ contact $\left(400 \mu \mathrm{m}^{2}\right)$. From this curve, an SB height $\left(\Phi_{n}\right)$ of $0.53 \mathrm{eV}$ is calculated.

Table 1

Extracted $\Phi_{n}, \eta$ and $R_{\mathrm{S}}$ of the Ni/Ge Schottky diodes with contact area of $10 \mu \mathrm{m}^{2}$.

\begin{tabular}{clll}
\hline Substrate $(\Omega \mathrm{cm})$ & $\Phi_{n}(\mathrm{eV})$ & $\eta$ & $R_{\mathrm{s}}(\Omega)$ \\
\hline $2-2.4$ & 0.52 & 1.12 & 30.77 \\
$0.13-0.15$ & 0.53 & 1.04 & 16.05 \\
$0.005-0.02$ & 0.52 & 1.09 & 11.72 \\
\hline
\end{tabular}


to investigate their Germanidation mechanism. Phase identification and crystallographic structure determination were carried out using XRD with $\mathrm{CuK} \alpha$ radiation $(\lambda=1.5418 \AA)$ in a $\theta-2 \theta$ geometry. Fig. 3 shows the XRD spectra for as-deposited and annealed $\mathrm{Ni} / \mathrm{Ge}$ samples for initial Ni thicknesses of $70 \mathrm{~nm}$. The initial $\mathrm{Ni}$ (111) peak at $44.68^{\circ}$ completely disappears after annealing indicating complete reaction of the $\mathrm{Ni}$ film into Ge. Peaks at $34.8^{\circ}$, $35.2^{\circ}, 44.2^{\circ}, 45.7^{\circ}, 53.8^{\circ}$ and $54.4^{\circ}$ are observed when the sample was annealed at $500^{\circ} \mathrm{C}$. These peaks are in excellent agreement with the $\theta-2 \theta$ pattern of the NiGe JCPDS standard. The peaks were identified as NiGe(111), (210), (211), (121), (002) and (301), respectively. No peaks corresponding to other $\mathrm{Ni}$-Germanides, e.g., $\mathrm{Ni}_{2} \mathrm{Ge}$ $\mathrm{NiGe}_{2}$, etc. are observed. This refers to the formation of only polycrystalline Ni-mono-Germanide (NiGe) phase forming at the annealing temperatures. For the $300^{\circ} \mathrm{C}$ annealed samples, the NiGe peaks are very weak, while after $400{ }^{\circ} \mathrm{C}$ annealing, the peaks become quite strong. It suggests that the solid-state reaction starts at $300^{\circ} \mathrm{C}$, and it substantially occurs at the annealing temperature of $500{ }^{\circ} \mathrm{C}$. The lattice constants of the formed $\mathrm{NiGe}$ are determined to be $a=5.81, b=5.37$ and $c=3.40 \AA$ from the XRD spectra, in agreement with the reported values [9].

The crystallite size $(t)$ of the grown $\operatorname{NiGe}(111)$ was investigated by taking further XRD scan within close intervals surrounding the peak. These are shown in Fig. 4 as a function of annealing temperature $(T)$. The crystallite sizes are calculated from the peaks using the Scherrer relation:

$t=\frac{0.9 \lambda}{d \cos \theta}$

where $d$ is the broadening of the peaks due to the crystallite size. It was observed that $t$ increases with increasing $T$.

The variation of thickness of the $\mathrm{Ni}$ and $\mathrm{Ni}-\mathrm{Ge}$ film as a function of annealing temperature $(T)$ was determined by SEM as presented in Fig. 5. This thickness is seen to increase with increasing $T$. Theoretically, the ratio of the atomic volume of $\mathrm{NiGe}$ and $\mathrm{Ni}$ is 2.44 . From Fig. 1, the ratio of the film thickness of $\mathrm{NiGe}$ at $500^{\circ} \mathrm{C}$ to that of $\mathrm{Ni}$ is 2.53 .

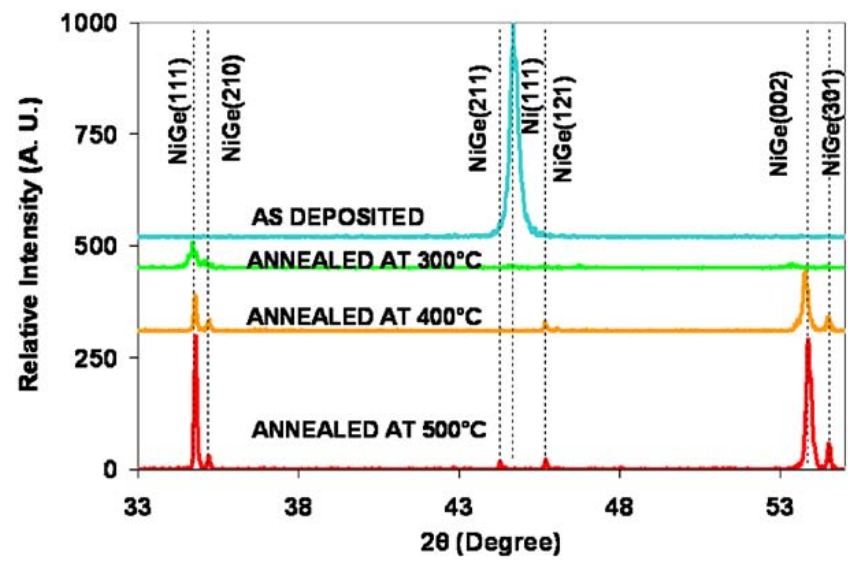

Fig. 3. The XRD spectra for the as-deposited and annealed Ni/Ge samples showing transformation from $\mathrm{Ni}$ to NiGe.

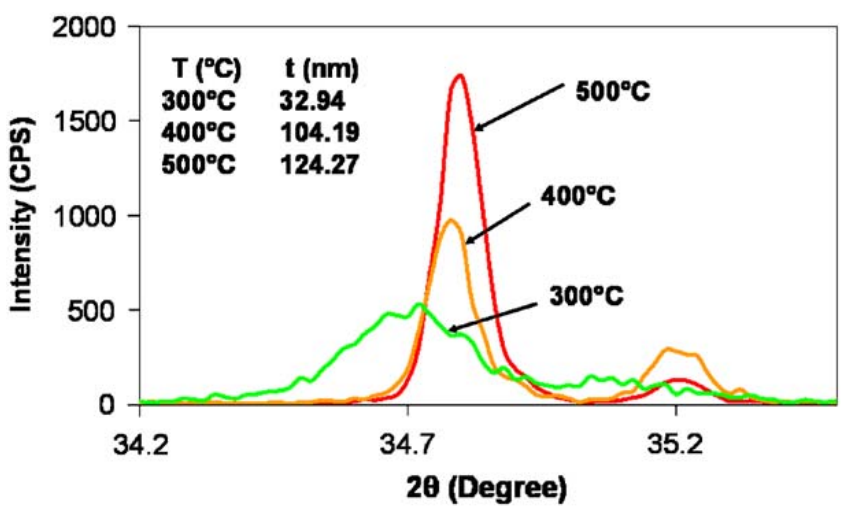

Fig. 4. XRD spectra showing the $\mathrm{NiGe}(111)$ peak of the $\mathrm{Ni}(70 \mathrm{~nm}) / \mathrm{Ge}$ samples when annealed at various temperatures. The calculated crystallite sizes are presented in the inset.

This confirms complete reaction of the $70 \mathrm{~nm} \mathrm{Ni}$ and formation of NiGe at that temperature.

In order to further exploit the Germanidation mechanism, the sheet resistance $\left(R_{\mathrm{sh}}\right)$ of the grown films was measured using the four-point probe method. The obtained $R_{\mathrm{sh}}$ values were multiplied by the film thicknesses to calculate the film resistivities $(\rho)$. The results are plotted as a function of annealing temperatures in Fig. 6. It is observed that $R_{\mathrm{sh}}$ decreased with increasing $T$. The measured $R_{\mathrm{sh}}$ of NiGe is $0.23 \Omega \square^{-1}$ when annealed at $500{ }^{\circ} \mathrm{C}$. This indicates full consumption of the $70 \mathrm{~nm}$ $\mathrm{Ni}$ and formation of Ni-mono-Germanide. The low $R_{\mathrm{sh}}$ could be attributed to the increase in crystallite size at $500{ }^{\circ} \mathrm{C}$ as observed. $\rho$ of $\mathrm{Ni}-\mathrm{Ge}$ also decreased when the films were annealed above $300^{\circ} \mathrm{C}$.

Typical current $(I)$ versus applied potential $(V)$ characteristics of the grown $\mathrm{Ni}(70 \mathrm{~nm}) / \mathrm{Ge}$ Schottky diodes under the as-deposited and annealed conditions on lowly resistive $(0.005-0.02 \Omega \mathrm{cm}) \mathrm{Ge}$ are presented in Fig. 7 for a contact pad size of $20 \mu \mathrm{m}^{2}$.

A high-quality rectifying behaviour ( $\sim 4-5$ orders in magnitude) is observed for all annealing conditions. Again, $\Phi_{n}, \eta$ and $R_{\mathrm{s}}$ are calculated assuming the TE model in the forward bias region and are presented in Table 2. The values of $\Phi_{n}$ are virtually constant at $\sim 0.52 \mathrm{eV}$. The corresponding hole barrier heights $\left(\Phi_{p}\right)$ are $\sim 0.14 \mathrm{eV}$ assuming a Ge bandgap of $0.66 \mathrm{eV}$. At low forward bias, there is a considerable overlap of the current curves of the various annealed samples as observed in Fig. 7. This indicates to both thermal stability and Fermi-level pinning in the Ge bandgap as the barrier height is independent of the metal work function. The reverse current at $1 \mathrm{~V}$ bias is $\sim 1 \mu \mathrm{A}$ for the various annealed diodes. This is a significant achievement as this value is $\sim 1$ order of magnitude smaller than the reported value in literature [7] for $\mathrm{NiGe} / \mathrm{Ge}$ diodes formed by evaporation on highly resistive $(4-6 \Omega \mathrm{cm}) \mathrm{Ge}$.

The low values of $\eta$ for the Schottky diodes presented in Table 2 indicate $\mathrm{TE}$ to be the dominant current conduction mechanism in the forward bias. The series resistance decreases with increasing $T$ (also observed in the inset of Fig. 7) indicating lower specific resistance of $\mathrm{NiGe}$ than Ni. This is consistent with the four-point probe measurement presented in Fig. 6. 

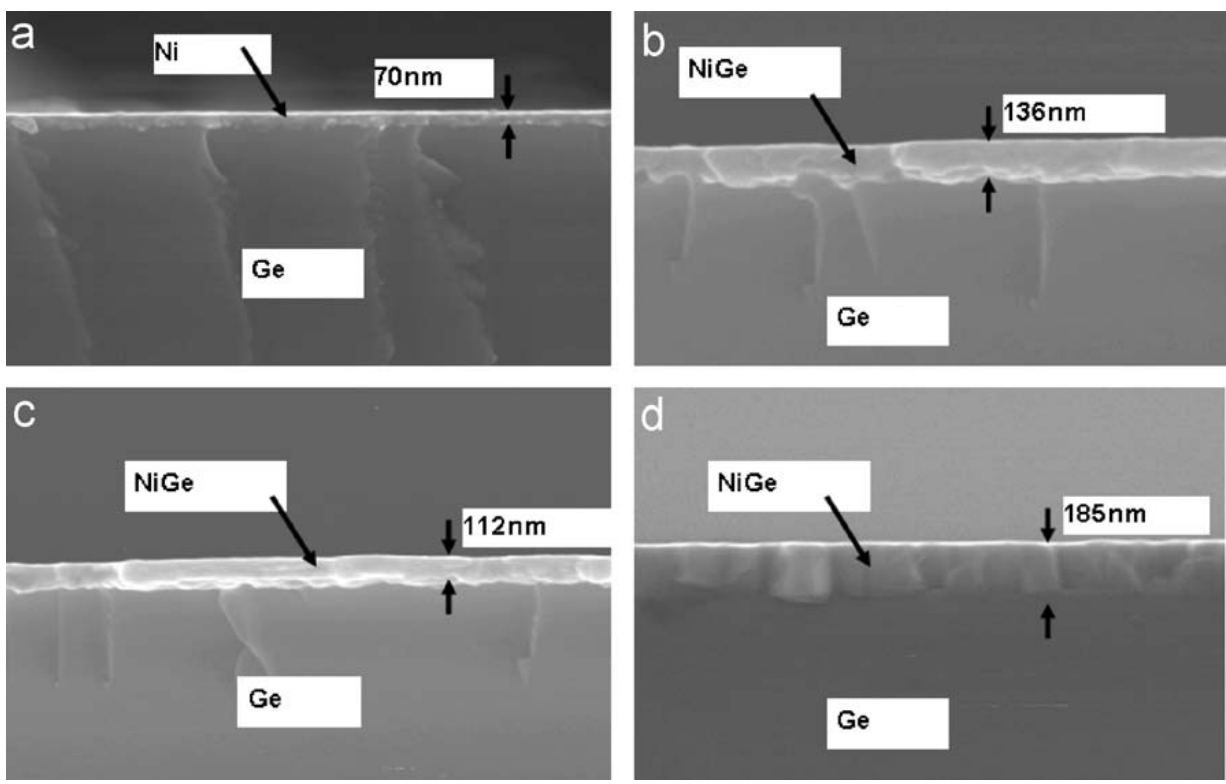

Fig. 5. Cross-sectional SEM images of the various Ni/Ge samples: (a) as-deposited, (b) annealed at $300{ }^{\circ} \mathrm{C}$, (c) annealed at $400{ }^{\circ} \mathrm{C}$ and (d) annealed at $500{ }^{\circ} \mathrm{C}$.

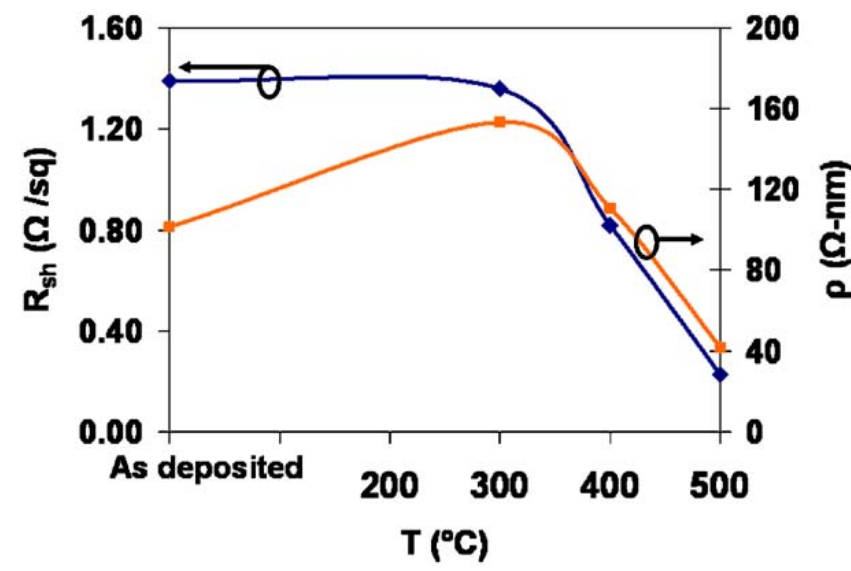

Fig. 6. $R_{\mathrm{sh}}$ and $\rho$ of $\mathrm{Ni}$ and $\mathrm{Ni}-\mathrm{Ge}$ films at various anneal temperatures. The initial Ni thickness was $70 \mathrm{~nm}$.

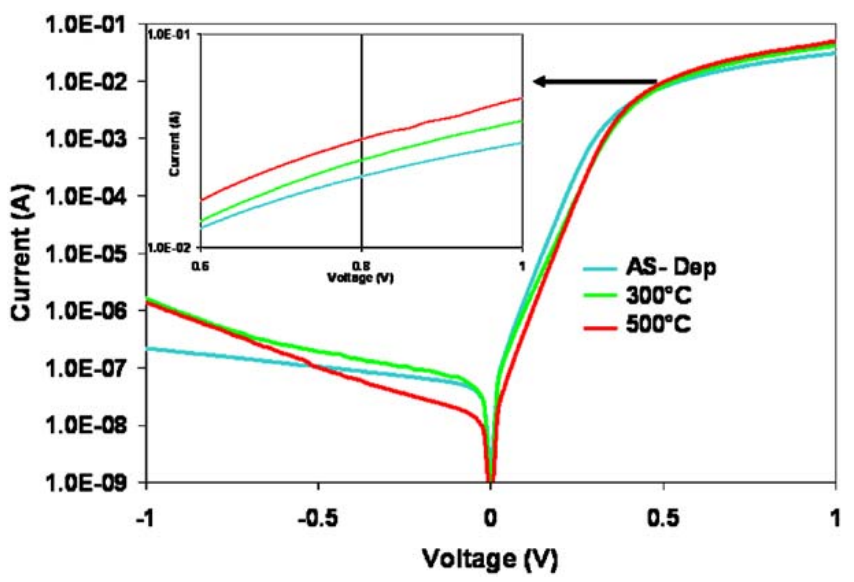

Fig. 7. $I-V$ characteristics of the Ni/Ge Schottky diodes, having a contact area of $20 \mu \mathrm{m}^{2}$, as a function of annealing temperatures. The high forward bias region is magnified in the inset.
Table 2

Extracted $\Phi_{n}, \eta$ and $R_{\mathrm{s}}$ of the Ni/Ge Schottky diodes with $20 \mu \mathrm{m}^{2}$ contact area as a function of $T$.

\begin{tabular}{llll}
\hline$T\left({ }^{\circ} \mathrm{C}\right)$ & $\Phi_{n}(\mathrm{eV})$ & $\eta$ & $R_{\mathrm{s}}(\Omega)$ \\
\hline None & 0.52 & 1.1 & 21.32 \\
300 & 0.52 & 1.27 & 14.79 \\
500 & 0.55 & 1.08 & 10.85 \\
\hline
\end{tabular}

\section{SB-MOSFET simulation}

The commercial TCAD simulator Sentaurus Device from Synopsys has been used for the simulation work that provided a self-consistent and fully coupled implementation of nonlocal tunnelling models of both electrons and holes. The devices were generated using the Sentaurus Structure Editor and its Meshing engine. The simulator was at first calibrated to model the Schottky diode $J-V$ results presented in Fig. 1. To accurately model the Schottky barrier MOSFET a fully coupled 2D simulation, was performed that included physical models e.g., bandgap narrowing effect and dependence of mobility to normal electric field. The drain current $\left(I_{\mathrm{d}}\right)$ versus gate voltage $\left(V_{\mathrm{g}}\right)$ characteristics for an SB PMOS with channel length $\left(L_{\mathrm{g}}\right)$ of $30 \mathrm{~nm}$, gate oxide thickness $\left(t_{\mathrm{ox}}\right)$ of $2 \mathrm{~nm}$ and body thickness of $10 \mathrm{~nm}$ were calculated as a function of various substrate doping densities $\left(N_{\mathrm{d}}\right)$ and are presented in Fig. 8. The source to drain subthreshold leakage current can be readily obtained from the curves at $V_{\mathrm{g}}=0$. It is found that for a fixed drain bias $\left(V_{\mathrm{d}}\right)$ of $-0.1 \mathrm{~V}$ the leakage current is $3 \times 10^{-9} \mathrm{~A} \mu \mathrm{m}^{-1}$ when Ge n-type doping density of $8.7 \times 10^{14} \mathrm{~cm}^{-3}$ was used. However, the leakage current decreased to $1.3 \times 10^{-9}$ and $3.6 \times 10^{-10} \mathrm{~A} \mu \mathrm{m}^{-1}$ when the substrate doping density was increased to $1.45 \times 10^{16}$ and $2.9 \times 10^{17} \mathrm{~cm}^{-3}$, respectively. Therefore, we propose that highly doped Ge substrate could be used for low leakage SB-MOSFET. At higher positive gate voltages, the leakage 


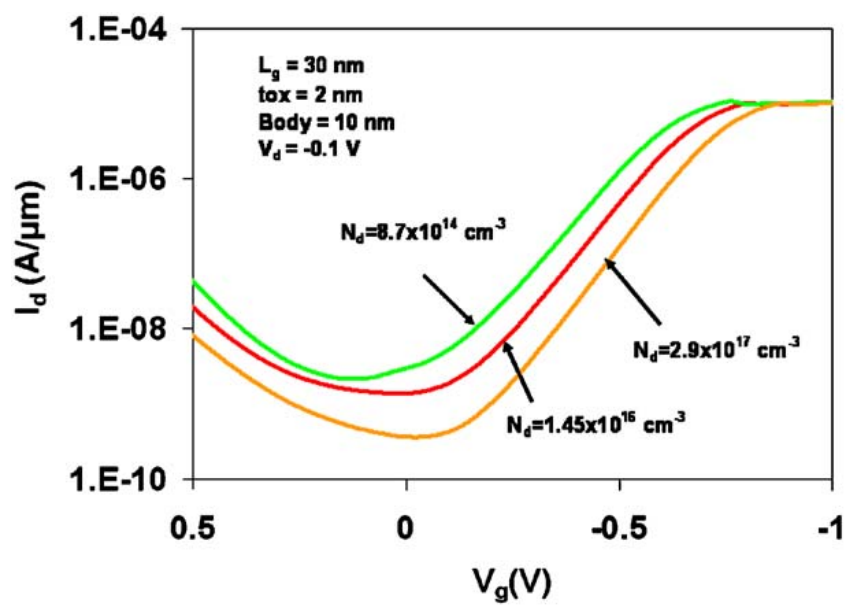

Fig. 8. Transfer characteristics of the Ge channel SB PMOS devices with a channel length of $30 \mathrm{~nm}$.

current is observed to increase for the various substrate doping densities. This is identified as the gate induced drain leakage (GIDL) and could be attributed to the low bandgap of the Ge substrate. GIDL could be alleviated by using a recessed channel and asymmetric source/drain Schottky contacts [10].

\section{Conclusions}

We report that $\mathrm{Ni} / \mathrm{Ge}$ Schottky barriers formed by electrodeposition on highly doped substrate shows high rectification with low leakage current which could be used for low leakage Ge-based SB-MOSFETs. The fabricated $\mathrm{Ni} / \mathrm{Ge}$ diodes were thermally stable up to $500^{\circ} \mathrm{C}$. The series resistances of $\mathrm{NiGe}$ decreased with annealing temperature which is important for high drive current in SB-MOSFETs. By numerical simulation, we are able to show that the source to drain subthreshold leakage current could be minimized by using highly doped Ge substrate. Therefore, we propose that electrodeposition could be used for source-drain formation of a highly doped Ge-based SB-MOSFET to achieve low subthreshold leakage current.

\section{References}

[1] Larson JM, Snyder JP. IEEE Trans Electron Devices 2006;53:1048.

[2] Zhu S, Li R, Lee SJ, Li MF, Du A, Singh J, et al. IEEE Electron Device Lett $2005 ; 26: 81-3$

[3] Li R, Yao HB, Lee SJ, Chi DZ, Yu MB, Lo GQ et al. Thin Solid Films 2006;504:28

[4] Kiziroglou ME, Zhukov AA, Abdelsalam M, Li X, de Groot PAJ, Bartlett PN, et al. IEEE Trans Magn 2005;41:2639.

[5] Kiziroglou ME, Zhukov AA, Li X, Gonzalez DC, de Groot PAJ, Bartlett PN, et al. Solid State Commun 2006;140:509.

[6] Ikeda K, Maeda T, Takagi S. Thin Solid Films 2006;508:359.

[7] Zhu S, Nakajima A. Jpn J Appl Phys 2005;44:L753.

[8] Sze SM, editor. Physics of semiconductor devices. New York: Wiley; 1981.

[9] Seger J, Zhang S-L, Mangelinck D, Radamson HH. Appl Phys Lett 2002;81:1978.

[10] Zhang Y, Wan J, Wang KL, Nguyen B. IEEE Electron Device Lett 2002;23:419. 